\title{
Developing Digital Archaeology for Young People: A Model for Fostering Empathy and Dialogue in Formal and Informal Learning Environments
}

\author{
Sierra McKinney*, Sara Perry ${ }^{\star}$, Akrivi Katifori ${ }^{\dagger}$ and \\ Vassilis Kourtis ${ }^{\dagger}$ \\ ${ }^{\star}$ University of York \\ ${ }^{\dagger}$ Athena Research \& Innovation Center, Greece
}

\begin{abstract}
While preconceptions of archaeology and cultural heritage are generally formed at a young age through exposure to mass media and teachings in formal and informal settings, the quality of these exposures is extremely variable and often fails to engage young people in meaningful ways. Although digital technologies may appear as tempting means to intervene in this meaning-making process, their application to archaeological pedagogy at the primary and secondary school
\end{abstract}

How to cite this book chapter:

McKinney, S., Perry, S., Katifori, A. and Kourtis, V. 2020. Developing Digital Archaeology for Young People: A Model for Fostering Empathy and Dialogue in Formal and Informal Learning Environments. In: Hageneuer, S. (ed.) Communicating the Past in the Digital Age: Proceedings of the International Conference on Digital Methods in Teaching and Learning in Archaeology (12-13 October 2018). Pp. 179-195. London: Ubiquity Press. DOI: https://doi.org/10.5334/ bch.n. License: CC-BY 4.0 
level can be superficial or result in the replication of existing problematic pedagogical approaches. However, while the challenges of weaving archaeological knowledge into primary and secondary education are considerable, the digital archaeology schoolroom is an untapped resource with potential for engendering individual learning, constructive group dialogue, good citizenship and larger social conscience.

After reflecting on common weaknesses with extant pedagogical methods, including the prevalence of digital tools that require solitary and passive use, we present an alternative approach to the archaeological education resource: a multi-component digital kit for use in formal and informal learning environments. Created as part of the EU-funded EMOTIVE Project, this kit's components (including $3 D$ printed objects, a virtual museum, and chatbot, which are usable independently but ideally deployed in tandem over a period of days or weeks) seek to nurture perspective-taking skills, close looking and listening skills, critical dialogue, and self-reflection to foster empathy among young people.

\section{Keywords}

Archaeology in Schools, Digital Media, Young People, Historical Empathy, Facilitated Dialogue

\section{Introduction}

As a discipline and field of practice, archaeology offers a powerful tool for education. The inherent ability of archaeology to evoke wonder, enchantment and powerful personal connections results in a pedagogy that can simultaneously engage, challenge and inform. While the potential for digitally mediated archaeological education is immense, recent research into the implementation of educational programmes has frequently privileged the post-secondary environment and, where primary and secondary studies have been attended to, the published literature primarily focuses back on the technological development of tools such as virtual reality and 3D modelling, rather than on their efficacy as teaching aids, suggesting gaps in understanding around current practice.

With the adoption of archaeology into formal curriculums for primary students in countries including Canada, England and Australia (Alberta Education 2007; Australian Curriculum 2015; British Columbia 2018; Department of Education 2013), and the continued presence of archaeology in informal learning environments such as clubs and museums, archaeological education for children and young people is an important area of development with the potential to engender individual learning, constructive group dialogue, good citizenship and larger social conscience. Furthermore, the growth of digital technologies has enabled archaeology to be taught to younger audiences using 
increasingly varied methods including virtual (VR) and augmented reality (AR), digital games, 3D modelling and printing, and virtual museums. However, these approaches can often replicate problematic elements of their analogue counterparts in that they provide solitary experiences, one-directional provision of information, and passive engagement. In such cases, the human elements of archaeology, and the associated benefits of an affective experience, can be lost. Instead, we argue for a model of archaeological education for children and young people that embraces the emotive elements of archaeology through the development of pre/historical empathy and the use of facilitated dialogue.

The following chapter grows out of the three-year European Commissionfunded EMOTIVE Project (EMOTIVE n.d.a; Katifori et al. 2019), an interdisciplinary research programme uniting eight institutional partners through work at cultural heritage sites across Europe, including two UNESCO-listed World Heritage Sites and various popular local attractions serving tens to hundreds of thousands of visitors per year. EMOTIVE is premised upon a growing body of scholarship that demonstrates the direct relationship between visitors' emotional experiences (e.g. feelings of wonder, provocation, and resonance generated through their engagement with these sites) and their heightened understanding of, attachment to and care for the sites and their exhibits in the short and longer term (see Perry 2019; Perry et al. 2017). In other words, the evidence suggests that it is through personal, emotional connections that humans are most likely to be primed to acquire knowledge about, protect and promote the archaeological record. EMOTIVE, then, aims to research, design, develop and evaluate methods and digital technologies that support cultural sites and interested communities (interpreted broadly to include museums, schools, heritage and archaeological destinations, spiritual and religious settings, galleries and other local and tourist destinations, community centres, citizen/interest groups, and more) in creating such emotional connections with heritage.

Our concern is that typical pedagogical approaches to heritage tend not only to devalue, ignore or misunderstand the importance of emotion but also neglect or misapply the capacities of digital media, therein undermining the learning outcomes and broader transformative social prospects of the subject matter. We outline here a conceptual model that aims to respond to this predicament, using dialogue fostered through children's social engagements with digital technologies to cultivate historical empathy. Below, we contextualise our work in relation to extant digital heritage initiatives for young people before going on to define historical empathy and facilitated dialogue, drawing particular inspiration from Endacott and Brooks (2013), Bormann and Campt (in Smithsonian n.d.) and the US National Park Service (2019b), and extending their approaches to address the more distant past via a focus on pre/historical empathy. We offer a summary of the application of our conceptual model in informal educational environments in the UK (tested with eight- to 15year-olds), 
noting that detailed analysis of our evaluations is available in McKinney (2018) and McKinney et al. (forthcoming). We then conclude with brief reflections on some of the key challenges confronting such work (and echoed by other researchers), which suggest the importance of informal learning environments for pursuing emotively engaging heritage outcomes.

\section{Overview of existing digital heritage for young people}

Preconceptions of archaeology and cultural heritage are formed from childhood, typically in relation to exposure to the media, formal classroom lessons and informal educational experiences. The quality of these exposures is extremely variable in their ability to be relevant and impactful for young people. In attempting to connect with children, many museums, schools and cultural institutions have turned to digital media - and digitally hosted resources that are available for printing - seemingly under the assumption that such resources will afford more resonance for students, not to mention convenience for teachers. Yet, the availability and quality of digital tools for children's archaeological education vary considerably, tending to privilege extremes - e.g. highly technical and expensive tools or simple pdfs; melodramatic narratives or a series of didactic facts.

Seeking to contextualise our work in relation to comparable pedagogical efforts, we conducted a cursory review of online educational resources, evaluating them against Beetham and Sharpe's (2007) expansion of Laurillards's (2002) typology of digital resources for learning. This typology outlines five basic forms of resource: narrative, productive, interactive, adaptive and communicative. Narrative resources ask users to engage with a representation (such as text, images or videos), which may be assimilative, in the sense that the user passively consumes them, or productive, wherein the user partakes in their creation. Productive resources consist of tasks that ask the user to manipulate or provide data, but, by our reckoning, this form of resource is very uncommon within the existing corpus of archaeological digital educational tools. Interactive resources return information on the basis of user input, such as quizzes or search engines. Within the existing corpus, interactive resources appear frequently, often as part of virtual museums or in the form of searchable artefacts or museum databases. Adaptive resources require continuous input from the user, such as virtual worlds or games, and, owing to the nature of this type of resource, they are becoming increasingly common with the rise of archaeogaming and VR/AR technology. Finally, communicative resources include tasks that emphasise interaction between individuals and groups, such as social media or messaging. As it relates to digital archaeological educational tools, digital communicative resources tend to occur in the form of public outreach on social media by archaeological sites or museums. However, the extent to which these offerings provide the opportunity to engage in bilateral 
communication can vary, resulting in resources that may be communicative or alternatively may be narrative in nature, depending on the level of engagement from the owner (e.g. the museum) of the social media site. An alternative and smaller subsection of communicative archaeological digital tools are chatbots, which offer an opportunity to engage in discussion with a virtual interface or robot even if their current implementations leave a lot to be desired (see Tzouganatou 2018).

Our review indicates that digitally hosted analogue materials are the most prevalent learning materials available for those seeking to teach about archaeology to young people. This category, which falls under the digital resource typology's assimilative narrative type, includes worksheets, lesson plans and other assets that are created with the explicit intention that they be printed prior to use. While these materials may be useful and engaging, their adoption of the affordances provided by digital technologies is minimal. As such, they often utilise formats traditionally found in the classroom, with a heavy emphasis on reading, identifying and reiterating facts, and solitary, passive use. Yet, the benefit of these digitally hosted analogue materials is their ease of use: they require few to no advanced or costly resources and can be employed by large groups of children simultaneously. Furthermore, they can be retrieved from many locations, including museum websites, archaeological professional societies and government-sponsored sites (Archaeology Scotland n.d.; National Park Service 2019a; Society for American Archaeology n.d.; University of Leicester n.d.), making them accessible to a seemingly wide audience. An excellent example of this type of tool is the Star Carr resource created by Henson (Star Carr Archaeology Project n.d.), which utilises storytelling and interactive activities to emphasise the human nature of prehistoric peoples.

An alternative approach can be found in the use of virtual museums and exhibits for pedagogical purposes. Virtual museums have the ability to embrace the affordances of the internet, including 3D walkthroughs, 3D artefact reconstructions, hyperlinks, videos, mini games and virtual digs (Friends of Bonnechere Parks 2006; Leicester City Council 2019; SFU Museum of Archaeology and Ethnography 2009). As such, depending on their application of these affordances, virtual museums can be adaptive or interactive, and even have the potential to be communicative. However, an iconic example, the Virtual Museum of Canada (VMC n.d.), reveals the often-disappointing implementation of these resources, wherein many fall into the assimilative narrative type. The majority appear to mimic a textbook rather than the halls of a museum, as they consist of a series of text-heavy pages with a small scattering of images, and their primary technological innovation consists of the inclusion of video. Indeed, many simply replicate existing analogue materials in html code. While this limited technical complexity of the VMC is likely due to lack of resources, the end result remains an uninspiring and, at times, onerous tool to use (but cf. the VMC's unique Journey into Time Immemorial (SFU 2008)). At the opposite extreme, large institutions, such as the Louvre and Vatican (Louvre 
Museum n.d.; Mvsei Vaticani n.d.), have digital museums that consist solely of virtual walkthroughs, which allow the user to digitally 'see' the museum but provide no information, interpretation or ability to focus on a specific work of art or artefact.

Furthermore, adaptive resources, such as VR, AR, serious games and 3D models and prints, are increasingly being deployed for teaching and learning, sometimes via web-based repositories and sometimes through offline services and bespoke projects. Indeed, existing research on digital tools for primary education has arguably favoured these technologies. However, the research typically explores them as isolated elements and focuses on the function of technology itself rather than its efficacy as a means of educating. Additionally, many of these approaches require expensive technology, access to research prototypes and/or a degree of digital expertise, which limits accessibility for users. Important recent exceptions include Di Giuseppantonio Di Franco et al.s (2019) combination of the affordances of 3D models with an historical inquiry-based learning methodology, which has demonstrated positive results in encouraging complex and critical forms of historical understanding among Tunisian primary and secondary students.

Even if easily accessible, the nature of the technology itself may manifest in problematical forms of engagement that limit pedagogical potential. For instance, VR is almost exclusively experienced by its users in an isolated, solitary fashion, and it frequently consists of passive engagement with the virtual environment. An exception to this predicament is Google Expeditions (Google 2019), which allows a teacher to 'guide' a class of students through a virtual environment augmented with information and text. However, even in this instance, in which the children are simultaneously participating in the same tour, each student remains isolated within their own headset. This is mitigated to a certain extent with the application of $A R$, as users can more easily share in the experience. However, AR presents its own challenges, as it is frequently designed to be used in a site-specific location, potentially limiting its accessibility.

Perhaps the most dynamic of the above-listed digital resources for children's education are archaeological games. As adaptive tools, with the potential to also become communicative, archaeological games have the ability to enable user agency and multiplayer social interaction in an immersive experience. Recent examples of this type of educational resource include Hiriart's (2019) sophisticated archaeogame prototypes that explore the lives of Anglo-Saxon families. Hiriart's work not only establishes the potential for games (played in formal educational settings) to foster higher-order thinking, challenge preconceptions and counter naïve conceptualisations of the past but also furnishes a wider theoretical model and design guidelines for others to create effective gaming-based 'personal encounters' that are meaningfully integrated with extant formal learning resources. 


\section{The argument for pre/historical empathy}

In contrast to the passive, didactic and solitary pedagogical techniques that are the basis of many of the resources discussed above, we suggest that a humanfocused practice, such as archaeology, requires a human-focused pedagogy. The concept of historical empathy offers a meaningful intellectual grounding upon which to build such a pedagogy, and it has obvious parallels with both the inquiry-based approach of Di Giuseppantonio Di Franco et al. (2019) and the historical thinking approach of Hiriart (2019). Collectively, these models seek to nurture richer personal engagements with heritage through methods that oblige students to see - or, indeed, embody - difference and to take the lead in navigating their own learning. Importantly, these methods also demand a degree of faith from educators, trusting in students to steer the process and negotiate complicated topics among themselves. The advantage of historical empathy, as we see it, is its measurable, tripartite nature (which also maps neatly onto the facilitated dialogue model that we outline below) and its future action orientation (forcing children's attention onto next steps and subsequent acts on the world).

Specifically, historical empathy is the 'process of students' cognitive and affective engagement with historical figures to better understand and contextualize their lived experiences, decisions, or actions' (Endacott \& Brooks 2013: 41). First introduced by archaeologist R.G. Collingwood in England (Collingwood 1939), the concept was subsequently developed internationally, with key research undertaken in Canada, the United States and Denmark, in addition to the UK. Studies have demonstrated that the application of historical empathy results in increased interest in the taught content (Endacott 2010; Kohlmeier 2006); an improved ability to retain content knowledge (Brooks 2011; Endacott \& Brooks 2013; Kohlmeier 2006) and to understand complex ideas (Endacott 2010; Foster 1999); and the development of the ability to establish connections and relationships between the past and the present (Brooks 2011).

The most recent model of historical empathy, created by Endacott and Brooks (2013), consists of a framework with three interrelated and interdependent endeavors' (p. 43): historical contextualisation, perspective taking and affective connection. This model was recently applied in a heritage context by Savenije and de Bruijn (2017) and has been more widely employed within the field of history education (de Leur, Van Boxtel \& Wilschut 2017; Efstathiou, Kyza \& Georgiou 2018; Ellenwood 2017).

The first of the three components, historical contextualisation, aims to provide students with critical information about significant historical events, figures and practices, in order to assist students in understanding cultural norms and perspectives informing the views of historic peoples. The second element, perspective taking, challenges students to view the past from alternative perspectives, considering their own personal experiences and beliefs in relation to 


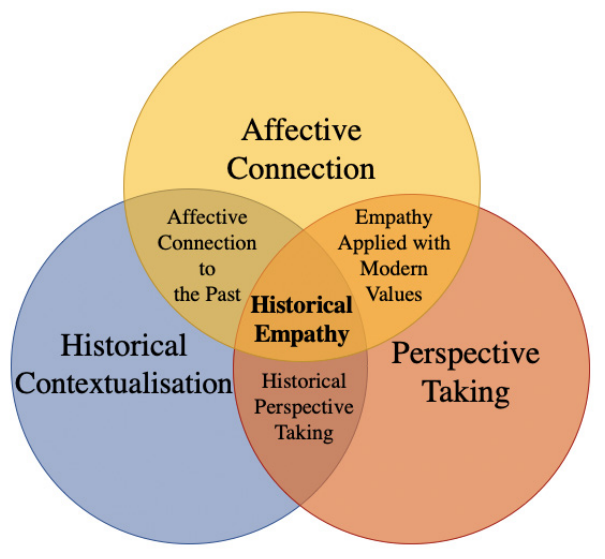

Figure 1: Diagram of historical empathy and its components (adapted from Endacott \& Brooks 2013: 44).

those of others, in order to better understand how a historical individual may have viewed their circumstances. The third component, affective connection, prompts students to recognise the human nature of past peoples, as individuals with their own emotions and complexities. In viewing the past through the lens of complex people, students are prompted to connect these experiences to their own lives and, in doing so, consider their actions in the future. It is in this final element that a key aspect of historical empathy is introduced: care. The ultimate aim of historical empathy is to develop a sense of care: a care to learn about the past, a care that events happened, a care for other people (past and present) and, lastly, a sense of care to apply the lessons learned from the past into the present (Barton \& Levstik 2004).

However, the historical empathy model has been applied almost exclusively in relation to the historical period (drawing upon historic sources, especially the written word), leaving out the vast majority of the human past and its empathetic potentials. The lack of engagement with this model in archaeology is perhaps unsurprising given the fragmentary material evidence available to connect people in the present with people from the distant past. Yet, other more intangible - mechanisms to forge such connections are widely available and are virtually unexplored within the discipline. Here we are referring to dialogue, and specifically the Arc of Dialogue - a model for facilitating dialogue developed by Tammy Bormann and David Campt (International Coalition of Sites of Conscience n.d.). Dialogue encourages individuals to share their unique views and experiences with the express goal of personal and collective learning' (Smithsonian n.d.: 4). As facilitated dialogue challenges participants to share personal experiences and beliefs, listen and examine factual 


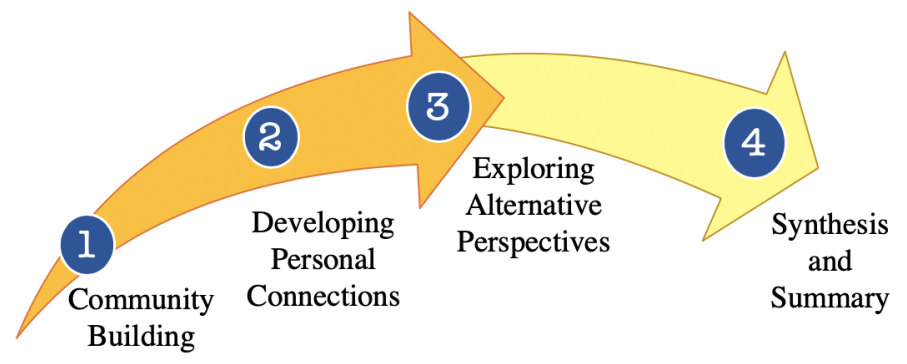

Figure 2: Arc of Dialogue (adapted from National Park Service 2019b: 11).

information presented to them, and consider the perspectives of others, it is a natural complement to historical empathy, and one means by which deep time and more distant human pasts may be explored. Furthermore, dialogic methods, including group discussion and debate, have been successfully used when teaching historic empathy in classroom environments (Endacott \& Pelekanos 2015; Jensen 2008; Kohlmeier 2006).

The Arc of Dialogue consists of four phases: community building, sharing personal experiences, further exploration of alternative perspectives, and summary and synthesis (National Parks Service 2019b: 11; Smithsonian National Museum of the American Indian n.d.: 4-5; Smithsonian n.d.: 6-10). The first phase introduces participants to the topic and one another, with the intention of developing an environment that invites and encourages participation. The second phase asks participants to share their personal connections with the topic, fostering a sense of care and affective connection. This is followed by the third phase, in which participants are challenged to listen to alternative views. They are encouraged to ask questions, reflect on the topic more broadly, and view things from the perspectives of others. Finally, the fourth phase summarises the discussion and prompts the participants to reflect on the discussion, their own beliefs and what they have learned.

\section{Pre/historic empathy through dialogue: EMOTIVE's digital education kit}

We have tested the efficacy of a dialogue-based pre/historic empathy model via the development of a digital education kit for the UNESCO World Heritage Site of Çatalhöyük in Turkey (whose components are extensible to other sites, contexts and audiences). ${ }^{1}$ The Exploration of Egalitarianism Digital Education

${ }^{1}$ While we discuss here our specific adaptation of the pre/historic empathy model for Çatalhöyük, we are separately developing each of the model's three components 


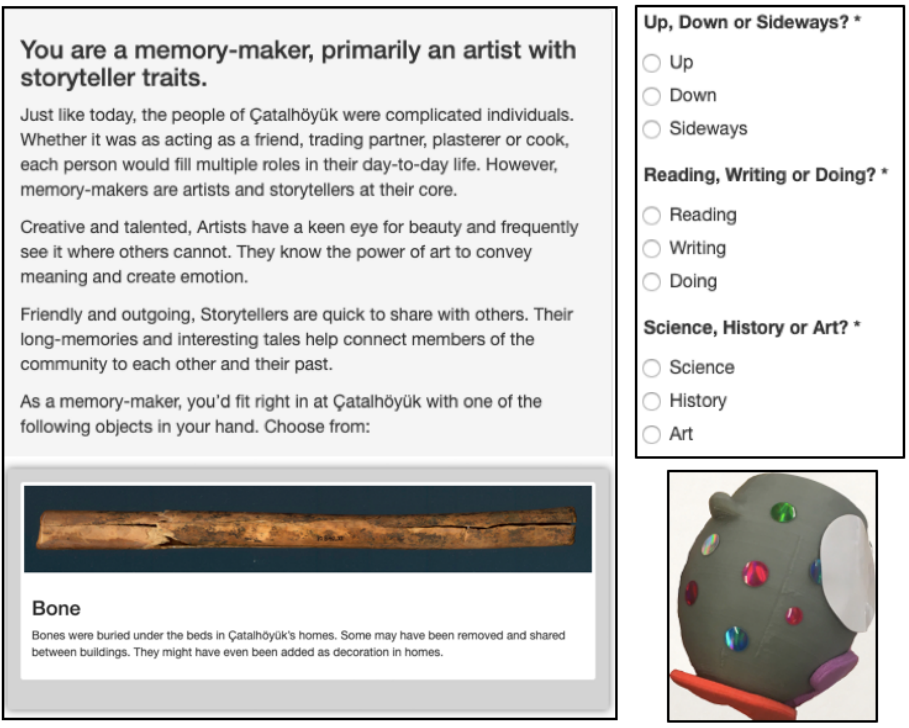

Figure 3: Elements of the Personality Quiz.

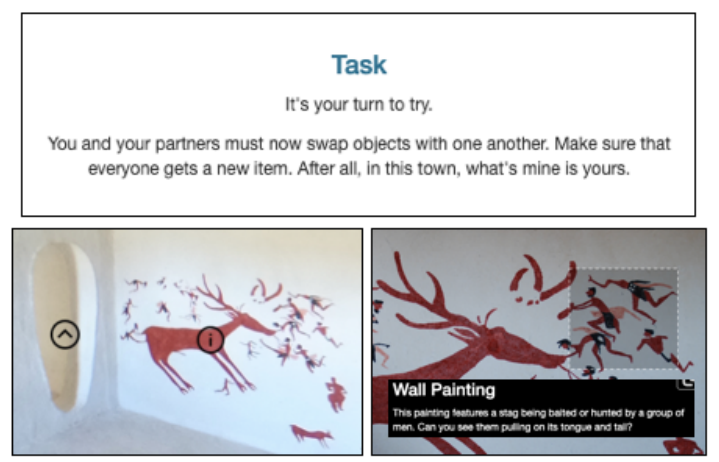

Figure 4: Example task and screenshots of the Egalitarian Trading Experience.

as generic tools that other sites, teachers and interested organisations and individuals can use to tailor the Kit to their needs and learning objectives. These tools include: (1) the Personality Quiz (a profiling quiz used to connect users to a specific role and related objects), created with EMOTIVE's Profiling Quiz Editor; (2) the 3D-moulded prints (replica artefacts that can be crafted quickly (in minutes) by the site or a user with plaster of Paris or modelling clay), created with EMOTIVE's Meta Moulds; (3) the Web Experiencing Tool (a web-based virtual representation of a site, visualised through interactive 360-degree photos), created with EMOTIVE's Floorplan Editor; (4) the Narralive Mobile App (an interactive digital storytelling 
Kit (hereafter referred to as the Kit) consists of three phases: the Welcome to Çatalhöyük Personality Quiz, an Egalitarian Trading Experience, and a Discussion with Bo the ChatBot (Figure 3). Each stage broadly correlates to one of the entwined components of historical empathy and a phase of the Arc of Dialogue (Figure 2). At the time of writing, the Kit is accessible for public use through the University of York Archaeology Department's Educational Resources webpage and on EMOTIVE's website (EMOTIVE n.d.b; University of York n.d.).

In the first stage, the Personality Quiz, participants answer a series of questions about themselves in order to reveal their own complex Neolithic personality and three potential 3D printed objects (Figure 3). These personalities have the dual purpose of matching a participant with an object and developing an affective connection by establishing a link from the object to their own personality. This introduces the users to the topic, as established in the first phase of the Arc of Dialogue.

Following on, participants tour a series of virtual houses (360-degree digital photographs of physical replicas of Çatalhöyük's Neolithic period buildings) in groups of two or three (Figure 4). The houses are visualised on computers through an interactive web-based app (using the Floor Plan Editor, a tool in development by members of the EMOTIVE team) wherein panoramic 360 -degree photos are enhanced with points of interest that offer a closer view of specific features as well as more information. The virtual walkthroughs are led by a mobile-based narrative (created via a digital storytelling authoring tool, also in development; Figure 5), which guides participants through an embodied experience of egalitarianism, in which they are asked to exchange and leave behind objects via collective decision-making. Through this embodied experience, participants are able to recognise and develop connections to their own lives, as outlined in the second phase of the Arc. During this component of the experience, the participants are provided with additional factual information to assist with historical contextualisation.

Finally, larger groups of five to eight users then come together to engage in a facilitated dialogue session with a chatbot (whose rules-based format is being elaborated by the EMOTIVE team for generic application; Figure 5). The chatbot replicates the Arc of Dialogue, resulting in a 'nesting doll effect' (Figure 6). As the chatbot guides the users through the dialogue, they are challenged to engage in perspective taking and synthesise what they learned throughout the entirety of the experience. In doing so, the chatbot fulfils the third and fourth phases of the Arc of Dialogue.

Thus, using the established pedagogies of historical empathy and the Arc of Dialogue as our guide, we have developed a resource that simultaneously applies

app for mobile devices), developed with the Narralive Storyboard Editor; and (5) the EMOTIVE Bot (a rules-based chatbot), built using the third-party SnatchBot (2019) software and grounded in EMOTIVE's Bot of Conviction model (Roussou et al. 2019). 


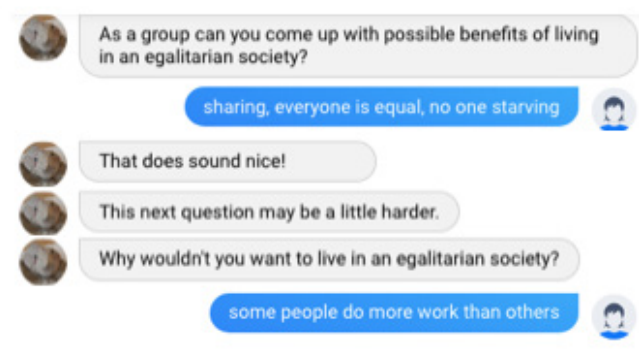

Figure 5: Screenshot of a conversation with Bo the Chatbot.

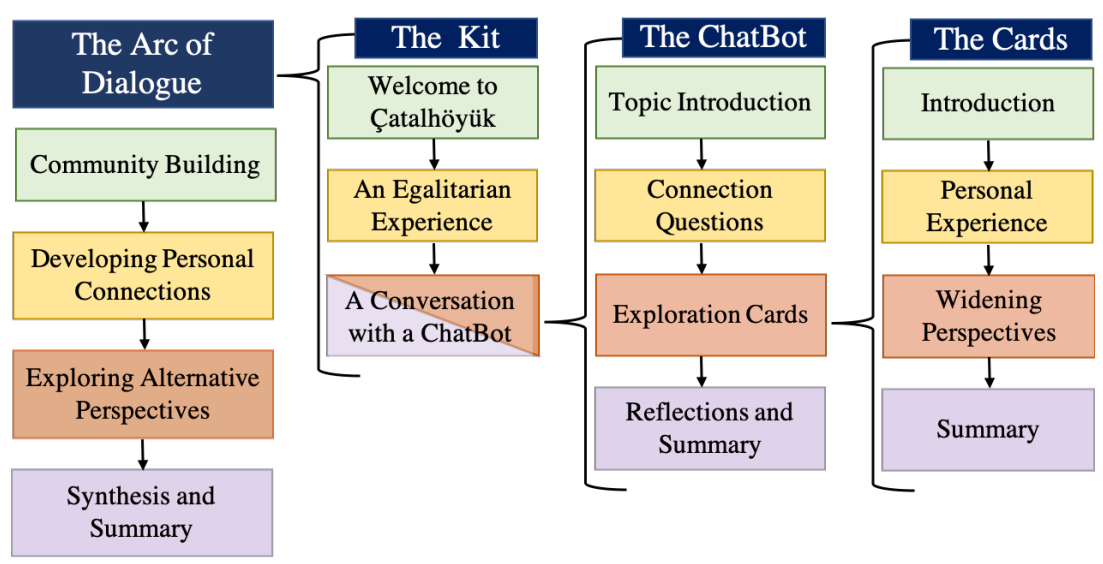

Figure 6: Schematic of the Digital Education Kit mapped onto the Arc of Dialogue. 'The Cards' refer to a specific component of the chatbot experience, whose specifics are outlined in McKinney (2018).

multiple digital technologies, including 3D prints, a chatbot, webpages and virtual walkthroughs, to create a digital resource for archaeology that emphasises collective, embodied and affective learning. In doing so, we aim to avoid replicating the problematic pedagogical strategies discussed at the beginning of this chapter. Indeed, we seek to bridge the extremes, creating an approach that develops resources that are both communicative and adaptive through the application of an affectively engaging and dialogic framework. Under this framework the technical educational tools are applied in a manner that is social, immersive, informative and encourages active bilateral engagement while all remaining accessible through a single webpage (McKinney 2019). Although it is complex in its various parts, we have simultaneously developed generic tools (see description in note 1), including a how-to guide for the creation of dialogic chatbots, to enable others to experiment in other contexts - playing with their 
content, adjusting how, in which order and when (if at all) they are deployed, and otherwise remixing them, knowing that individually and collectively they function to enhance emotive outcomes among users.

Our tests of the pre/historical empathy model suggest that it is best applied in informal educational environments, owing to the challenges of integrating any new resource into the formal learning setting (also see comparable discussions in Di Giuseppantonio Di Franco et al. (2019) and Hiriart (2019)). While this point requires further exploration (see McKinney et al., forthcoming), the informal application of this approach is arguably its strength, as young people are empowered to survey ideas that might otherwise sit awkwardly within their formal schooling, and that might more fluidly fold into their home lives, where empathetic (or non-empathetic) relations are so strongly created and reinforced.

However, in presenting our model, we do not wish to dictate a strict framework that must be followed. Rather we hope here to have provided a small degree of inspiration for future possibilities for digital archaeological educational resources: accessible tools that foster a sense of personal connection or care, empathy, dialogue, and enchantment.

\section{Acknowledgements}

This work is part of the EMOTIVE Project, which has received funding from the European Union's Horizon 2020 research and innovation programme under grant agreement No. 727188. The authors would like to thank Angeliki Tzouganatou and Sophia Mirashrafi for significant intellectual contributions that laid the foundations for our work, as well as the larger the EMOTIVE team. We also wish to thank the young people and leaders of the Young Archaeologists' Clubs who participated in our formative studies.

\section{References}

Alberta Education (2007). Social Studies Kindergarten to Grade 12, [pdf] Available at: https://education.alberta.ca/media/3273004/social-studies-k-6-pos. pdf [Accessed 1 April 2019].

Archaeology Scotland (n.d.). Heritage Resources Portal. [online] Archaeology Scotland. Available at: https://archaeologyscotland.org.uk/learn-resources [Accessed 20 March 2019].

Australian Curriculum (2015). History: Sequence of Content 7-10 Strand: Knowledge and Understanding. [pdf] Available at: http://docs.acara.edu.au/ resources/History_7-10_-_Sequence_of_content.pdf [Accessed 1 April 2019].

Barton, K.C. and Levstik, L.S. (2004). Teaching History for the Common Good, London: Routledge. 
Beetham, H. and Sharpe, R. (2007). Rethinking Pedagogy for a Digital Age, Abingdon: Routledge.

British Columbia (2018). BC's New Curriculum Social Studies 3. [online] Government British Columbia. Available at: https://curriculum.gov.bc.ca/ curriculum/social-studies/3 [Accessed 1 April 2019].

Brooks, S. (2011). Historical empathy as perspective recognition and care in one secondary social studies classroom. Theory \& Research in Social Education, 39(2): 166-202.

Collingwood, R.G. (1939). An Autobiography, London: Oxford University Press.

de Leur, T., Van Boxtel C. and Wilschut, A. (2017). 'I saw angry people and broken statues': Historical empathy in secondary history education. British Journal of Educational Studies, 65(3): 331-352.

Department of Education (2013). National Curriculum in England: History Programmes of Study. [online] Government UK. Available at: https:// www.gov.uk/government/publications/national-curriculum-in-englandhistory-programmes-of-study/national-curriculum-in-england-historyprogrammes-of-study\#key-stage-3 [Accessed 1 April 2019].

Di Giuseppantonio Di Franco, P., Winterbottom, M., Galeazzi, F. and Gogan, M. (2019). Ksar Said: Building Tunisian young people's critical engagement with their heritage. Sustainability, 11(5): 1373, DOI: https://doi.org/10.3390/ su11051373.

Efstathiou, I., Kyza, E.A. and Georgiou, Y. (2018). An inquiry-based augmented reality mobile learning approach to fostering primary school students' historical reasoning in non-formal settings, Interactive Learning Environments, 26(1): 22-41.

Ellenwood, T.D. (2017). Historical empathy: Judging the people of the past in a secondary social studies classroom. Learning to Teach, 6(1). [online] University of Toledo. Available at: https://www.utdl.edu/ojs/index.php/ learningtoteach/article/view/233/115 [Accessed 29 April 2019].

EMOTIVE (n.d.a). Emotive. [online] Emotive Project. Available at: https:// emotiveproject.eu [Accessed 18 February 2019].

EMOTIVE (n.d.b). Exploration of Egalitarianism: A Digital Education Kit. [online] Emotive Project. Available at: http://athena.emotiveproject.eu/ schoolkit [Accessed 22 August 2019].

Endacott, J.L. (2010). Reconsidering affective engagement in historical empathy. Theory \& Research in Social Education, 38(1): 6-47.

Endacott, J.L. and Brooks, S. (2013). An updated theoretical and practical model for promoting historical empathy. Social Studies Research and Practice, 8(1): $41-58$.

Endacott, J.L. and Pelekanos, C. (2015). Slaves, women, and war! Engaging middle school students in historical empathy for enduring understanding. The Social Studies, 106(1): 1-7. 
Foster, S. (1999). Using historical empathy to excite students about the study of history: Can you empathize with Neville Chamberlain? The Social Studies, 90(1): 18-24.

Friends of Bonnechere Parks (2006). How to Dig. [online] Virtual Museums. Available at: http://www.virtualmuseum.ca/sgc-cms/expositionsexhibitions/esprits-spirits/English/Dig/digdown.html [Accessed 23 March 2019].

Google (2019). What Is Expeditions. [online] Google. Available at: https:// support.google.com/edu/expeditions/answer/6335093?hl=en [Accessed 15 March 2019].

Hiriart, J. (2019). Gaming the Past: Designing and Using Digital Games as Historical Learning Contexts. PhD. University of Salford, UK.

International Coalition of Sites of Conscience (n.d.). Facilitated Dialogue. [pdf] Sites of Conscience. Available at: https://www.sitesofconscience.org/ wp-content/uploads/2019/01/Dialogue-Overview.pdf [Accessed 30 April 2019].

Jensen, J. (2008). Developing historical empathy through debate: An action research study. Social Studies Research and Practice, 3(1): 55-66.

Katifori, A., Roussou, M., Perry, S., Drettakis, G., Vizcay, S. and Philip, J. (2019). The EMOTIVE Project - emotive virtual cultural experiences through personalized storytelling. In: CIRA@EuroMed 2018, Dublin: IEEE, pp. 11-20, [pdf] Available at: http://ceur-ws.org/Vol-2235/paper2. pdf [Accessed 29 April 2019].

Kohlmeier, J. (2006). 'Couldn't she just leave?': The relationship between consistently using class discussions and the development of historical empathy in a 9th grade world history course. Theory \& Research in Social Education, 34(1): 34-57, DOI: https://doi.org/10.1080/00933104.2006.10473297.

Laurillard, D. (2002).Rethinking University Teaching: A Conversational Framework for the Effective Use of Learning Technologies, London: Routledge/Falmer.

Leicester City Council (2019). The Jewry Wall. [online] Government Leicester. Available at: http://jewrywallstory.leicester.gov.uk [Accessed 21 March 2019].

Louvre Museum (n.d.) Experience Louvre. [online] YouVisit. Available at: https://www.youvisit.com/tour/louvremuseum [Accessed 20 March 2019].

McKinney, S. (2018). Generating Pre-Historical Empathy: An Examination of a Digital Classroom Kit. MSc. University of York, UK.

McKinney, S. (2019). Exploration of Egalitarianism Digital Education Kit. [online] GitHub. Available at: slmck.github.io [Accessed 20 March 2019].

McKinney, S., Perry, S., Katifori, A., Kourtis, V. and Lougiakis, C. (forthcoming). Generating Pre-Historic Empathy in Classrooms. Journal of Community Archaeology and Heritage.

Mvsei Vaticani (n.d.). Raphael's Room. [online] Vatican Museum. Available at: http://www.museivaticani.va/content/museivaticani/en/collezioni/musei/ stanze-di-raffaello/tour-virtuale.html [Accessed 20 March 2019]. 
National Park Service (2019a). Teacher Resources. [online] National Park Service. Available at: https://www.nps.gov/archeology/Public/teach. htm\#plans [Accessed 20 March 2019].

National Park Service (2019b). Forging Connections through Audience Centered Experiences Workbook. [online] Google Drive. Available at: https://drive. google.com/file/d/1vvAsiyORvBI1kDOU6SXVk76DWmHfR6lV/view [Accessed 8 April 2019].

Perry, S. (2019). The Enchantment of the Archaeological Record. European Journal of Archaeology, 22(3): 354-371.

Perry, S.E., Roussou, M., Economou, M., Young, H. and Pujol-Tost, L. (2017). Moving beyond the virtual museum: Engaging visitors emotionally. In: 23rd International Conference on Virtual Systems \& Multimedia (VSMM), Dublin: IEEE, pp. 1-8.

Roussou, M., Perry, S., Katifori, A., Vassos, S., Tzouganatou, A. and McKinney, S. (2019). Transformation through provocation? Designing a 'bot of conviction' to challenge conceptions and evoke critical reflection. In: Proceedings of the 2019 CHI Conference on Human Factors in Computing Systems. ACM Digital Library, 627.

Savenije, G.M. and de Bruijn, P. (2017). Historical empathy in a museum: uniting contextualisation and emotional engagement. International Journal of Heritage Studies, 23(9): 832-845, DOI: https://doi.org/10.1080/ 13527258.2017.1339108.

SFU Museum of Archaeology and Ethnography (2008). A Journey into Time Immemorial. [online] Simon Fraser University. Available at: http://www.sfu. museum/time. [Accessed 10 April 2019].

Smithsonian (n.d.). Beyond Bollywood: Indian Americans Shape the Nation. [pdf] Sites Archives. Available at: http://sitesarchives.si.edu/exhibitions/exhibits/beyondbollywood/BeyondBollywoodDialogueToolkit.pdf [Accessed 16 April 2019].

Smithsonian National Museum of the American Indian (n.d.). Americans: $A$ Dialogue Toolkit for Educators. [pdf] Available at: http://nmai.si.edu/sites/1/ files/pdf/education/NMAI-Americans-dialogue-toolkit.pdf [Accessed 16 April 2019].

SnatchBot (2019). SnatchBot. [online]. Available at: https://snatchbot.me [Accessed 19 April 2019].

Society for American Archaeology (n.d.). K-12 Activities \& Resources. [online] Society for American Archaeology. Available at: https://www.saa.org/education-outreach/teaching-archaeology/k-12-activities-resources [Accessed 20 March 2019].

Star Carr Archaeology Project (n.d.) Schools. [online] Starr Carr Project. Available at: http://www.starcarr.com/schools.html [Accessed 15 March 2019].

Tzouganatou, A. (2018). Can heritage bots thrive? Toward future engagement in cultural heritage. Advances in Archaeological Practice, 6(4): 377-383. 
University of Leicester (n.d.). Teaching Resources. [online] University of Leicester. Available at: https://le.ac.uk/archaeology/outreach/for-teachers/ teaching-resources [Accessed 20 March 2019].

University of York (n.d.) Educational Resources for Schools. [online] University of York. Available at: https://www.york.ac.uk/archaeology/ schools [Accessed 16 August 2019].

Virtual Museum of Canada (n.d.). Virtual Exhibitions. [online] Virtual Museum of Canada. Available at: http://www.virtualmuseum.ca/virtual-exhibits/ type/virtual-exhibits [Accessed 20 March 2019]. 
